\title{
A Practice of Choosing Gamification-based Personas
}

\author{
Shunli Liu \\ Faculty of Art, Computing \& Creative Industry, \\ Universiti Pendidikan Sultan Idris, \\ TanjongMalim, Perak, 35900, Malaysia. \\ Muhammad Zaffwan Idris \\ Faculty of Art, Computing \& Creative Industry, \\ Universiti Pendidikan Sultan Idris, \\ TanjongMalim, Perak, 35900, Malaysia.
}

\begin{abstract}
This study contributes our entire research project on museum user experience (UX), and the purpose of the paper is to provide knowledge in practice for choosing Gamification-motivated personas. As the player's motivation fundamentally drives the outcomes, the Bartle Test of Gamer Psychology reigning from types of players was employed as a persona tool for identifying personas representing distinct intrinsic motivations. Specifically, adhering to the philosophy of user-centric intrinsic motivation, Bartle drew on an extensive range of sources to identify four types of players: achievers, socializers, explorers, and killers (we re-name killers as attackers). By analyzing the gamer psychology, it can be connected the player types to the intrinsic needs in the Self-Determination Theory (SDT). From a methodological point of view, the combination approach of quantitative and qualitative methods with constantly narrowing the scope of candidate can benefit trustworthiness. As a practical study, this paper not only analyzes the principles, but also provides a detailed persona selection procedure.
\end{abstract}

Keywords: Persona; Gamification; Bartle Test; User Experience (UX); Museum.

\section{INTRODUCTION}

Compared to real life, gamers can achieve more in the online world. In recent years, a large and growing literature suggests that the utilization of elements and skills from game enhances motivation for participation and learning (e.g., Brigham, 2015). In addition, even more incredible is that the game and the work will be equal (Zichermann \& Cunningham, 2011). Zichermann and Cunningham (2011) further pointed out that, in any system, the player's motivation ultimately drives the outcomes. Accordingly, as an important section of our research on museum experience, this research focuses on how we employed the Bartle Test of Gamer Psychology based on players' type to identify personas with distinct motivations.

\section{PURPOSE OF THE PAPER}

The purpose of this paper is to identify Gamification-based personas for our museum user experience (UX) related research, and to provide knowledge in practice for other researchers. In the research on museum UX, the persona technique is expected to solve the urgent issue of understanding the visitor composition of the museum propose (Tian, 2018). Coincidentally, Falk and Dierking (2013) also made a similar statement: "it is important to understand who your visitors are and develop an interpretive plan will meet their needs and interests." These provide hints for investigating museum experiences using persona technique. However, most of previous literature only proposed the player types model and the Bartle Test as a tool, and lacked a detailed and scientific description of the principles and procedures (Zichermann \& 
Cunningham, 2011; Konert et al., 2013; Nicholson, 2015; Liu \& Zaffwan, 2019). The origin of this paper is to fill this gap.

\section{LITERATURE REVIEW}

Much of the current literature on UX pays particular attention to persona technique. Preferably, the target of experience is based on the hypothesis that the experience is exactly related to the specific needs or interests of the user you created, which leads to the theme of persona. Specifically, Persona usually refers to a fictional character that represents a hypothesized user group with shared interests, common behaviour patterns, or demographic and geographical similarities (Stickdorn et al., 2018; Law \& Leicester, 2018). In recent years, the literature on Gamification has been increasing, and many authors believed that Gamification is a way to exploring users' distinct motivations, engagements, and experiences (Zichermann \& Cunningham, 2011; Döpker et al., 2013; Hamari \& Koivisto, 2015). These give some hints about the use of persona technique for museum experience investigation.

Although studies related to learning have generally focused on games for many years, the literature on Gamification has been increasing over the years. More specifically, despite the fact that Gamification originated in the digital media industry, the application scope of Gamification does not need to focus only on digital forms since the distinction between digital and nondigital projects is becoming increasingly blurred in recent years (Deterding, Khaled, Nacke, \& Dixon, 2011). Once the definition is mentioned, there is no agreed definition of Gamification. Despite this, some definitions made it clear that Gamification is a way to increase user engagement by adding game elements (Deterding et al., 2011; Zichermann \& Cunningham, 2011; Hamari \& Koivisto, 2015). In particular, their propositions illustrate using game elements to help accomplish other things, that is, solve all non-game work problems in life through the use of frames from games. On the other hand, however, research shows that Gamification of rewards is suitable for short-term purposes. Over time, the role of rewards should gradually diminish and should be replaced by continued meaningful participation (Nicholson, 2015). As Nicholson (2012) commented: "meaningful Gamification encourages a deeper integration of game mechanisms into non-game contexts." Accordingly, Nicholson (2012) introduces and supports the concept of Meaningful Gamification achieving the longterm change, which emphasizes intrinsic motivations for people's engagement in activities. The author further pointed out: "removing the scoring elements from a Gamification context encourages a focus on the integration of play". This indicated Meaningful Gamification is not using a points system. Overall, intrinsic motivations are more motivated than external motivations (Deci \& Ryan, 2012; Nicholson, 2015).

Intrinsically motivated activities refers to those individuals find interesting and would do in the absence of operationally separable consequences (Deci \& Ryan, 2000, 2015). Further, Deci and Ryan (2012) said: "If someone engaged in an activity freely without being rewarded and found it highly interesting and enjoyable, the person would be intrinsically motivated." Compared to relying on external motivation, the author demonstrated that it is beneficial to carry out a work for user-centric intrinsic motivations. In a user-centric philosophy, the SelfDetermination Theory (SDT) shows how to build a system that helps users find their own motivations for participation by building intrinsic motivation (Ryan \& Deci, 1985). As a motivational theory, SDT investigates a large-scope of situations across gender, culture, age, and socioeconomic status by focusing on the psychological level (Deci \& Ryan, 1985, 2015). In the SDT theory, the following three basic psychological needs have been proposed: the needs for Competence, Autonomy, and Relatedness (Figure 1). 
Figure 1. The Self-Determination Theory (SDT)

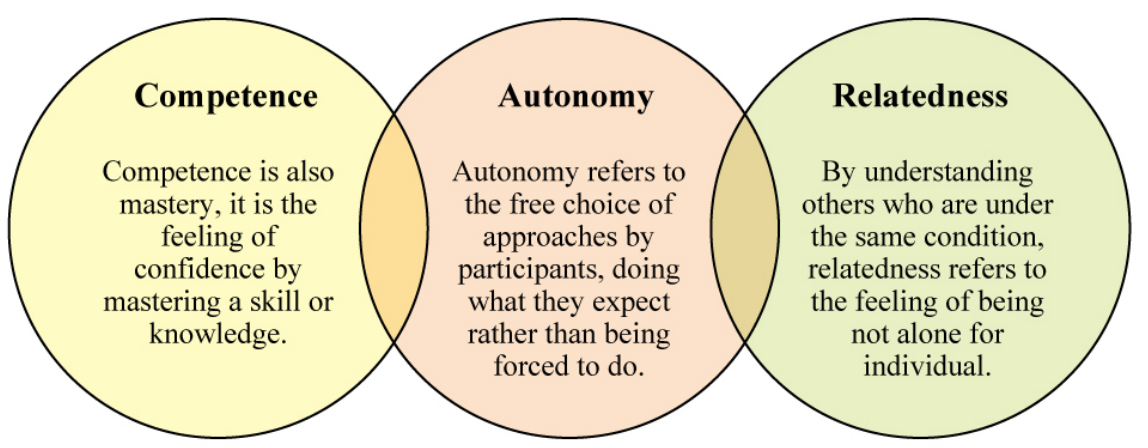

Three Basic Psychological Needs in the Self-Determination Theory (SDT)

Having discussed the intrinsic motivation, now return and re-examine the theme of Gamification. Briefly, the origins of Gamification are the players. That is, in any system, the player's motivation ultimately drives the results. Therefore, understanding player motivation is most essential to construct a efficient Gamified system (Zichermann \& Cunningham, 2011). Adhering to the philosophy of user-centric intrinsic motivation, Bartle (2004) drew on an extensive range of sources to identify four types of players: achievers (A), socializers (S), explorers (E), and killers (K) (we re-name killers as attackers). In brief, achievers want to book results, socializers want to collaborate, explorers want to understand, and attackers want to win. By analyzing the framework of gamer psychology - types of players proposed by Bartle, Nicholson (2015) connected the player types to the three categories of intrinsic needs in SDT, and concluded as follows: using Gamification systems, Socializers tend to meet and engage with others, they are interested in the Relatedness concept in SDT; try to break the boundaries of the Gamification system, explorers desire to participate in breadth, they value the concept of Play and pay special attention to the Autonomy element; Achievers are looking for a feeling of accomplishment, they highly value the Competence (Mastery) needs; Attackers expect competition and conquest and value the Mastery element in SDT (Figure 2).

Figure 2. Framework of gamer psychology (Liu \& Zaffwan, 2018)

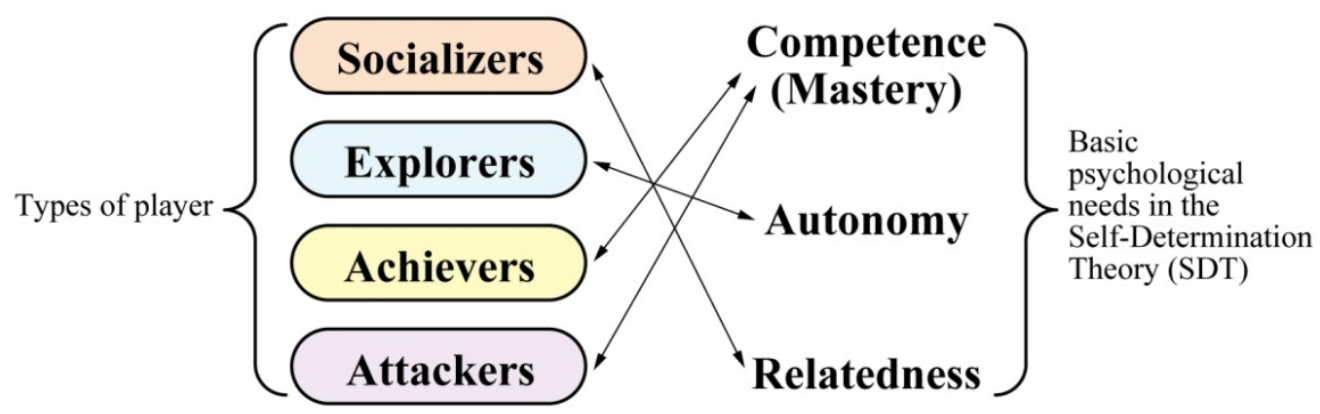

\section{CHOOSING GAMIFICATION-BASED PERSONAS: PRINCIPLES AND PROCEDURES}

In order to recruit personas to explore museum service experience, the Bartle Test questionnaire will be employed and distributed. The principle of this test will be introduced below, and the procedures of persona selection will also be explained.

\section{The Bartle Test of Gamer Psychology}

Based on the above taxonomy established by Bartle, Andreasen and Downey developed a questionnaire (GamerDNA test) for the Bartle Test of Gamer Psychology to identify gamers' playing style preference that predominates in a group of players. According to Konert, Göbel, and Steinmetz (2013), this test already collected data of more than 200,000 recipients. 
However, the version of the Bartle test is now offline. Thus, based on the same underlying data/questions as the GamerDNA test, Dr Matthew Barr who works at the University of Glasgow has implemented his own version (http://matthewbarr.co.uk/bartle/).

We corresponded with Barr and he gave the consent for us to use his implementation of the online test in our research. Furthermore, he emailed us the questions pool and key principles for formulating the test. Drawing on an extensive range of references, especially the mail exchange with Barr, we know that there exist 39 questions in the pool, in detail the number of groups for each combination are: S/A (7), S/E (6), S/K (7), E/A (6), E/K (7) and K/A (6). Accordingly, the script takes 30 questions randomly but checks that there are an equal number of questions for each player type combination. In this way, one of the choices relates to one specific playing style preferences. Thus the questionnaire works by asking questions for each combination of two different Bartle playing style preferences (e.g., socializer vs. achiever) and adding the numbers to get your own score. For instance, if one participant chooses the first option in the following socialiser vs. achiever question, he or she adds 1 to his or her socializer (S) score; conversely, if the second option is selected, it will add 1 to achiever (A) score.

Which do you enjoy more on a MUD?

A.Getting the latest gossip $(+S)$

B.Getting a new item $(+\mathrm{A})$

Consequently, the result of the Bartle Test is known as the 'Bartle Quotient'. Specifically, the 'Bartle Quotient' is computed according to the individual answers that grant a $200 \%$ entirety in four categories of preferences, without any separate style achieving above $100 \%$. For example, a user get a result with "90\% socializer, 60\% achiever, 40\% explorer, and 10\% killer", which indicates the player's motivation for playing is collaborating or interacting with others more than alternative style of interests. This result may be abbreviated as SAEK.

\section{Procedures of Persona Selection}

The persona identification procedures cover two phases. Firstly, the respondents were categorized into four categories based on the test results, and secondly, four ultimate personas were selected from those four types of respondents by combining quantitative and qualitative methods.

\section{Classifying Respondents}

The first phase in this stage is to choose who will participate in the survey. For convenience, the participants invited to answer the Bartle Test online questionnaire are 126 college students from my six classes. Since the potential "observer effect" is reduced to some extent due to the coordination between teachers and students, thus hopefully results trustworthy data. Before the survey task, I first scheduled time and held meetings with each class. During meetings, I sent everyone the URL of the questionnaire. However, the task for distributing questionnaires to respondents was not the major purpose of meetings. The most important thing is to explain to them my research proposal, the intention of the questionnaire, and how to operate on a technical level.

In this investigation, I asked them to send test results in screenshots to the online group via WeChat sharing. Accordingly, I collected the test results that everyone shared online. For instance, the screenshot below shows a test result for one of respondents with "87\% socializer, $67 \%$ explorer, $47 \%$ achiever, and $0 \%$ killer", which indicates this respondent regards collaboration as the main intention. Therefore, according to its highest score item (87\%), this persona is regarded as a socializer (Figure 3). 
Figure 3. A screenshot of test result

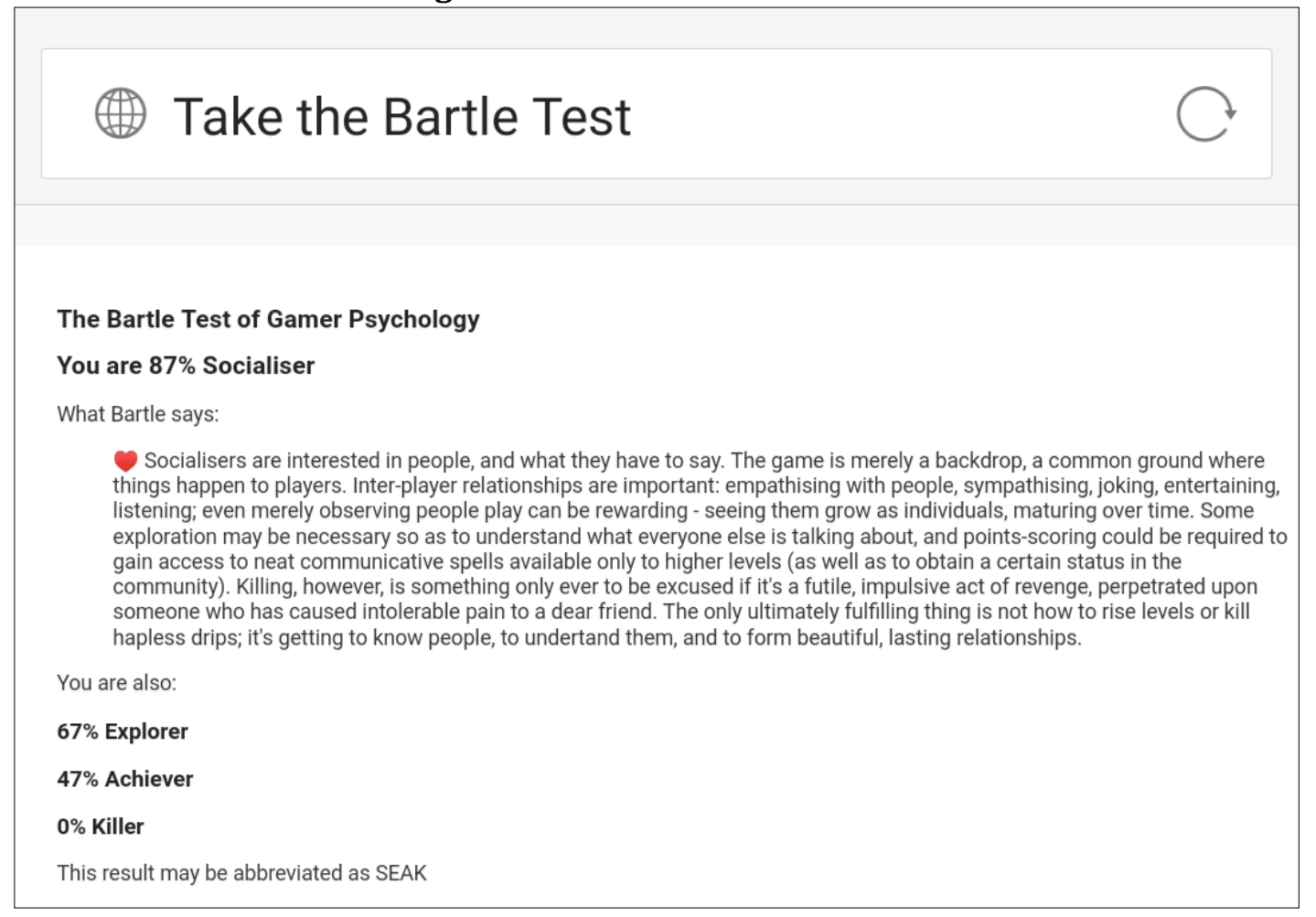

Next, the majority of respondents who completed the test submitted their screenshots of the results and this project collected a total of 99 test results from six classes (a total of 126 students). Then based on the highest scoring of these four categories, the researcher can determine which player type the 99 respondents belong to. By the assistance of the Microsoft Office Excel software for statistics, we acquired 122 results from 99 initial results by assorting the test results. Below is an excerpt from the results in the form of a table (Table 1). Surprisingly, it was found in the test results that some respondents have their two or more equal dominant identify-related characteristics, which determines the overall preferences of their composite type. 
Table 1. An excerpt from the results

\begin{tabular}{|c|c|c|c|c|}
\hline $\begin{array}{l}\text { Respondents with } \\
\text { 122 Results } \\
\text { (excerpt) }\end{array}$ & $\begin{array}{c}\text { S } \\
\text { (Socializer) } \%\end{array}$ & $\begin{array}{c}\mathrm{E} \\
\text { (Explorer) }\end{array}$ & $\begin{array}{c}\text { A } \\
\text { (Achiever) } \%\end{array}$ & $\begin{array}{c}\text { At } \\
\text { (Attacker) \% }\end{array}$ \\
\hline \multicolumn{5}{|l|}{ Socializers (37) } \\
\hline Cao Xiangyi & 87 & 67 & 47 & 0 \\
\hline Guo Qi & 80 & 53 & 13 & 53 \\
\hline Yuan Zhu & 80 & 47 & 20 & 53 \\
\hline Zuo Chaodan & 53 & 53 & 53 & 40 \\
\hline \multicolumn{5}{|l|}{$\ldots$} \\
\hline \multicolumn{5}{|l|}{ Explorers (33) } \\
\hline Chen Hongfan & 60 & 93 & 40 & 7 \\
\hline An Lijuan & 60 & 87 & 20 & 33 \\
\hline ZhangBIinhua & 60 & 80 & 27 & 33 \\
\hline Zuo Chaodan & 53 & 53 & 53 & 40 \\
\hline \multicolumn{5}{|l|}{$\ldots$} \\
\hline \multicolumn{5}{|l|}{ Achievers (28) } \\
\hline Zhou Mingwen & 33 & 40 & 80 & 47 \\
\hline Chang Ningbo & 40 & 27 & 80 & 53 \\
\hline Yang Siqi & 33 & 27 & 73 & 67 \\
\hline Zuo Chaodan & 53 & 53 & 53 & 40 \\
\hline \multicolumn{5}{|l|}{$\ldots$} \\
\hline \multicolumn{5}{|l|}{ Attackers (24) } \\
\hline Wu Huijuan & 53 & 20 & 40 & 87 \\
\hline He Ruili & 53 & 20 & 47 & 80 \\
\hline Yang Qian & 20 & 40 & 60 & 80 \\
\hline Liu Haiyue & 13 & 60 & 47 & 80 \\
\hline
\end{tabular}

\section{Selecting Desirable Personas}

After discussing how to divide the 'candidates' into four categories, the following explores practices for selecting ultimate personas from the above respondents. Frankly, this is a process of continuously narrowing the sample. Actually, most respondents have a dominant characteristic, which determines their overall preference. Participants can hereafter be judged which player type he or she predominantly belongs to according to which category achieve the highest score among the four. In addition, another essential criterion is the difference between the highest score and the second highest score is extremely large.

Firstly, this project selected several candidates from each of the four categories (S, E, A, At) who are most likely to become the desirable personas (Table 3.2). The reason why we focused on some candidates and not just the highest score was that I thereafter employed multiple other criteria to improve the rationality of the persona selection. Furthermore, another criterion is the difference between the highest score and the second highest score, the bigger the difference, the better.

After incorporating the main measures "high score" and the second specification "high difference", I set two specific criteria that are indispensable: (1) The percentage of the highest category is greater than or equal to 80\%; (2) The difference between the highest score and the second highest one is greater than or equal to $20 \%$. By specifying these two standards, I 
initially identified three socializers, two explorers, two achievers, and four attackers (Table 2). The above is to use a quantitative method to make the selection, relying entirely on the numbers in the test results.

Table 2. Selection criteria of desirable personas.

\begin{tabular}{|c|c|c|c|c|c|c|c|c|c|}
\hline \multirow[b]{2}{*}{ Candidates } & \multicolumn{4}{|c|}{$\begin{array}{c}\text { Four types of players' } \\
\text { playing style preference (\%) }\end{array}$} & \multirow[b]{2}{*}{$\begin{array}{l}\text { The } \\
\text { Highest } \\
\text { Subtracts } \\
\text { Second } \\
\text { Highest } \\
\text { (\%) }\end{array}$} & \multirow[b]{2}{*}{$\begin{array}{l}\text { Did You } \\
\text { Comprehend } \\
\text { the } \\
\text { Questionnaire } \\
\text { and Complete } \\
\text { it by Yourself? }\end{array}$} & \multirow[b]{2}{*}{$\begin{array}{l}\text { Is the Test } \\
\text { Result } \\
\text { Consistent } \\
\text { with Your } \\
\text { Motivation? }\end{array}$} & \multirow{2}{*}{$\begin{array}{l}\text { How Often Do } \\
\text { You Play } \\
\text { Games? } \\
\text { 1. Very } \\
\text { Frequently } \\
\text { 2. Frequently } \\
\text { 3. Sometimes } \\
\text { 4. Seldom } \\
\text { 5. Rarely } \\
\text { 6. Never } \\
\end{array}$} & \multirow[b]{2}{*}{$\begin{array}{l}\text { Selected as } \\
\text { Personas }\end{array}$} \\
\hline & $S$ & $\mathbf{E}$ & A & At & & & & & \\
\hline Socializers & $\geq 80$ & & & & $\geq 20$ & & & & \\
\hline Cao Xiangyi & 87 & 67 & 47 & 0 & 20 & $\sqrt{ }$ & $\sqrt{ }$ & 2. Frequently & $\sqrt{ }$ \\
\hline Guo Qi & 80 & 53 & 13 & 53 & 27 & $\sqrt{ }$ & Uncertain & 5. Rarely & \\
\hline Yuan Zhu & 80 & 47 & 20 & 53 & 27 & $\sqrt{ }$ & $\sqrt{ }$ & 4. Seldom & \\
\hline Explorers & & $\geq 80$ & & & $\geq 20$ & & & & \\
\hline $\begin{array}{l}\text { Chen } \\
\text { Hongfan }\end{array}$ & 60 & 93 & 40 & 7 & 33 & $\sqrt{ }$ & $\sqrt{ }$ & 3. Sometimes & $\sqrt{ }$ \\
\hline An Lijuan & 60 & 87 & 20 & 33 & 27 & $\sqrt{ }$ & $\sqrt{ }$ & 3. Sometimes & \\
\hline Achievers & & & $\geq 80$ & & $\geq 20$ & & & & \\
\hline $\begin{array}{l}\text { Zhou } \\
\text { Mingwen }\end{array}$ & 33 & 40 & 80 & 47 & 33 & $\sqrt{ }$ & $\sqrt{ }$ & 3. Sometimes & $\sqrt{ }$ \\
\hline $\begin{array}{l}\text { Chang } \\
\text { Ningbo } \\
\end{array}$ & 40 & 27 & 80 & 53 & 27 & $\sqrt{ }$ & $\sqrt{ }$ & 5. Rarely & \\
\hline Attackers & & & 1. & $\geq 80$ & $\geq 20$ & & & & \\
\hline Wu Huijuan & 53 & 20 & 40 & 87 & 34 & $\sqrt{ }$ & Uncertain & 6. Never & \\
\hline He Ruili & 53 & 20 & 47 & 80 & 27 & $x$ & Unknown & 6. Never & \\
\hline Yang Qian & 20 & 40 & 60 & 80 & 20 & $\sqrt{ }$ & $\sqrt{ }$ & 3. Sometimes & $\sqrt{ }$ \\
\hline Liu Haiyue & 13 & 60 & 47 & 80 & 20 & $\sqrt{ }$ & $\sqrt{ }$ & 3. Sometimes & \\
\hline
\end{tabular}

From a methodological point of view, the combination of quantitative and qualitative methods to narrow the scope of candidates is expected to make the selected personas more trustworthy. Accordingly, after narrowing down the personas pool, the researchers furthermore contacted these previously selected candidates through face-to-face short interviews and WeChat interviews, the main purpose of which was to further narrow down the scope of persona candidates. The questions in the interview are "Did you comprehend the questionnaire and complete it by yourself?" "Is the test result consistent with your motivation?" "How often do you play games?" To make it easier for respondents to answer this question, some answer options are provided. For example, the answer options based on the Semantic Differential Scale were ranged from "Very Frequently" to "Never" to determine how often a participant plays the game (Table 3.2).

Considering all of these procedures, it illustrates that it is necessary to combine all factors to make the desired selection. For example, when determining the persona of achiever, two candidates in this category have the same score. However, for Zhou Mingwen, the difference between the highest score and the second highest score is greater than that of Chang Ningbo. Additionally, Zhou Mingwen did not hesitate to say that he often plays game, so she was finally determined the achiever. When identifying the persona of attacker, after excluding these two candidates who have never plays game, the other two candidates are same in every respect according to the data in above table. In this case, we had an in-depth exchange with the two candidates and found that Yang Qian has a better understanding of the game. I also found that 
he was very decisive and specific in answering my questions. Follow a similar idea, qualitative methods were used to supplement the inadequacy of context for the number, and finally all four personas (one socializer, one explorer, one achiever, and one attacker) with different motivations were identified.

With the four personas based on player types being identified, this study initially involves four personas as respondents in order to further gather in-depth and detailed data. For intuition, each persona is described as a persona card, all of which help researchers find a distinct motivation that museum services should meet. Due to limited space, this paper shows only one card, the other three personas also use the same format (Figure 4).

Figure 4. The persona card: socialize

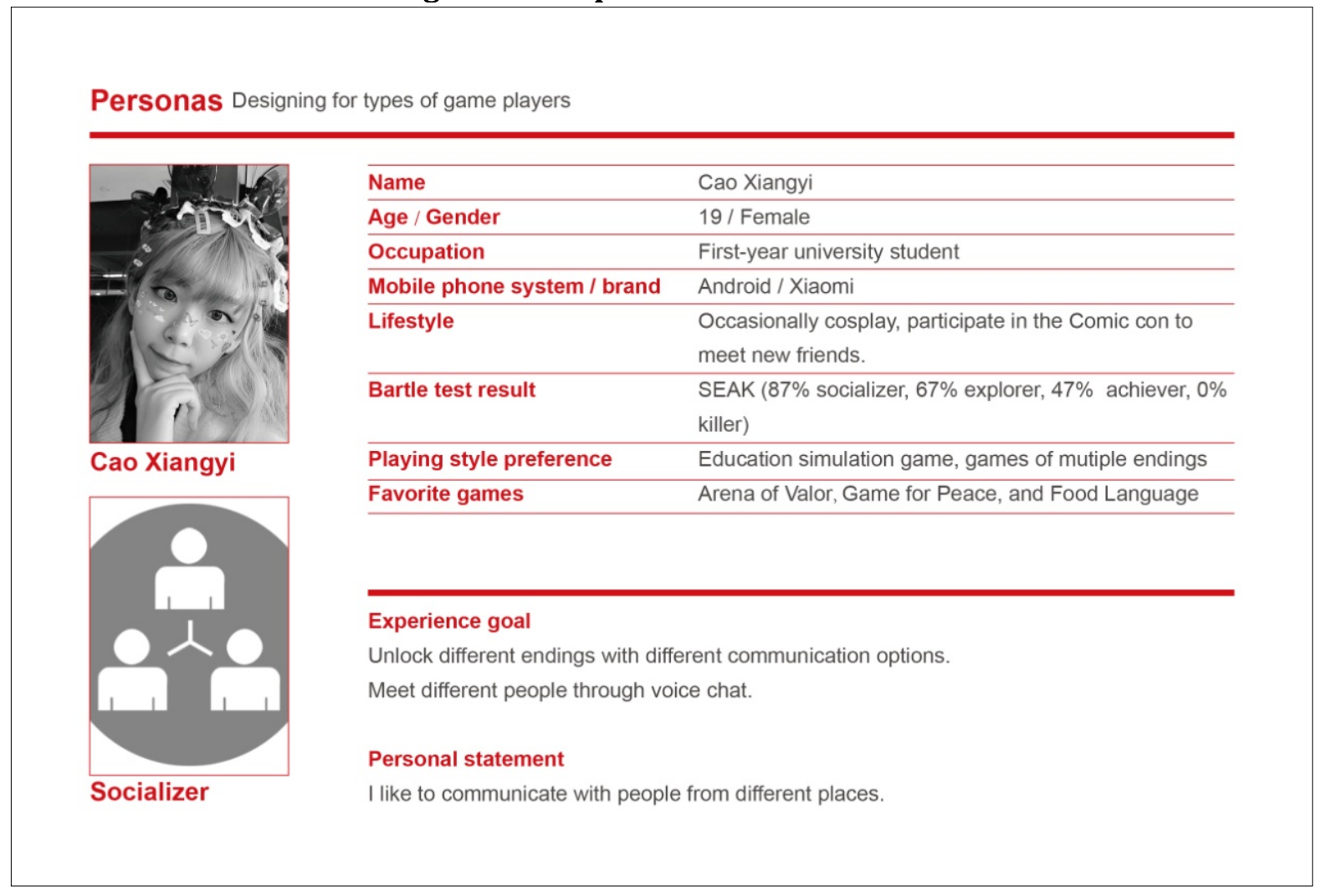

\section{DISCUSSION AND CONCLUSION}

This work has employed Gamification perspective to create personas for our museum UX research project to help understand different types of users. Previous literature almost just proposed the player types model and the Bartle Test, lacking a detailed and scientific description of the principles and procedures (Zichermann \& Cunningham, 2011; Konert et al., 2013; Nicholson, 2015; Liu \& Zaffwan, 2019). By contrast, this study not only explained the principle of the questionnaire, but also explored a detailed procedure of selecting desirable personas by continuously narrowing down the candidate scope. Specifically, the procedure includes how the questionnaire was distributed and collected; the respondents are divided into four categories according to the test results; and select the specific desirable personas from the four types of respondents. To conclude, in the process of selecting specific desirable personas, not only rely on quantitative data, but also combine interviews as qualitative method to make the selected personas more reliable. 


\section{References}

Bartle, R. A. (2004). Designing Virtual Worlds. US: New Riders.

Brigham, T. J. (2015). An Introduction to Gamification: Adding Game Elements for Engagement. Medical Reference Services Quarterly, 34(4), 471-480. https://doi.org/10.1080/02763869.2015.1082385

Deci, E. L., \& Ryan, R. M. (2000). The "What" and "Why" of Goal Pursuits: Human Needs and the Self-determination of Behavior. Psychological Inquiry, 11(4), 227-268. https://doi.org/10.1207/S15327965PLI1104_01

Deci, E. L., \& Ryan, R. M. (2012). Handbook of Self-determination Research (2nd ed.). US: University Rochester Press.

Deci, E. L., \& Ryan, R. M. (2015). Self-Determination Theory. International Encyclopedia of the Social \& Behavioral Sciences, 11, 486-491. https://doi.org/10.1016/B978-0-08-097086-8.26036-4

Deterding, S., Khaled, R., Nacke, L., \& Dixon, D. (2011). Gamification: Toward a Definition. CHI 2011 Gamification Workshop Proceedings, (January 2011), 12-15.

Döpker, A., Brockmann, T., \& Stieglitz, S. (2013). Use Cases for Gamification in Virtual Museums. Informatik 2013, Informatik Angepasst an Mensch, Organisation Und Umwelt: Tagung Vom 16. - 20. September 2013 in Koblenz; 43rd Meeting of the German Informatics Society, (September 2013), 2308-2321.

Falk, J. H., \& Dierking, L. D. (2013). Museum Experience Revisited (2nd ed.). Left Coast Press.

Hamari, J., \& Koivisto, J. (2015). Why Do People Use Gamification Services? International Journal of Information Management, 35(4), 419-431. https://doi.org/10.1016/j.ijinfomgt.2015.04.006

Konert, J., Göbel, S., \& Steinmetz, R. (2013). Modeling the Player, Learner and Personality: Independency of the Models of Bartle, Kolb and NEO-FFI (Big5) and the Implications for Game Based Learning. In Proceedings of the 7th European Conference on Game Based Learning (ECGBL) (pp. 329-335).

Law, E. L., \& Leicester, L. E. (2018). From UX Design Methods to Service Design Methods: Is it just a Matter of Scalability? In Experience Design Meets Service Design - Method Clash or Marriage? workshop in conjunction with CHI'18. Montreal, Canada.

Liu, S. L., \& Zaffwan, M. I. (2018). Constructing A Framework of User Experience for Museum Based on Gamification and Service Design (Vol. 04007, pp. 1-5). Luoyang, China.

Liu, S. L., \& Zaffwan, M. I. (2019). Exploring Museum Service Experience Using Gamification-based Personas with Distinct Motivations. In IOP Conference Series: Materials Science and Engineering (pp. 3-8). Luoyang, China. https://doi.org/10.1088/1757-899X/573/1/012020

Nicholson, S. (2012). A User-Centered Theoretical Framework for Meaningful Gamification. In Games+ Learning+ Society (Vol. 8, pp. 223-230). Madison, WI. https://doi.org/10.1007/978-3-319-10208-5_1

Nicholson, S. (2015). A RECIPE for Meaningful Gamification. (T. Reiners \& L. C. Wood, Eds.), Gamification in Education and Business. New York.

Ryan, R. M., \& Deci, E. L. (1985). Intrinsic Motivation And Self-determination in Human Behavior. New York: Plenum.

Stickdorn, M., Hormess, M. E., Lawrence, A., \& Schneider, J. (2018). This Is Service Design Doing: Applying Service Design Thinking in the Real World. O'Reilly Media, Incorporated.

Tian, J. (2018). Summary of the 2017 Annual Conference of the Archaeological \& Heritage Museum of the China Museum Association. Newsletter of China Museums, (2), 19-24.

Zichermann, G., \& Cunningham, C. (2011). Gamification by Design: Implementing Game Mechanics in Web and Mobile Apps. US: O’Reilly Media, Inc. 